\title{
REFLEXIONES PARA UN MARCO, METODOLOGICO DE LA PROBLEMÁTCA AMBIENTAL
}

\author{
Ricardo V. Santes Alvarez \\ Colegio de la Frontera Norte, Tijuana
}

\section{INTRODUCCIÓN}

Los tiempos actuales se significan por cambios sumamente rápidos y dramáticos en la sociedad y la naturaleza. La intrincada red de pequeños y grandes problemas de orden económico, pero también político, demográfico, ecológico e ideológico que vive el planeta -aparentemente tan separados todos ellos tanto en tiempo como en espacio-, ha venido conformando un impensado e inconmensurable problema global que tiene repercusiones en todos los rincones de los ambientes social y físico.

La cuestión ambiental, que tal es la denominación de esa problemática que nadie sabe con certeza cómo empezó, cuáles son sus particularidades -si es que las tiene-, hacia dónde va, o cómo resolverla -si ello puede hacerse-, trasciende estratos sociales y económicos, rebasa la política e incluso las nacionalidades. Se trata del problema de la humanidad en las generaciones actuales y futuras, como también lo es de toda la vida terrestre.

El ambiente físico, la "naturaleza", siempre ha sido objeto de uso del ser humano a partir de que éste apareció en el planeta, por lo que un problema de tipo ambiental ha estado ahí, latente. Ello significa que desde sus orígenes, $e l$ hombre ha causado problemas al ambiente; empero, al inicio esas afectaciones resultaban intrascendentes por varias razones: las formas de uso y explotación del sistema físico eran apenas agresivas, además de bajas en intensidad, y servían para satisfacer la demanda de pocos consumidores. Por otra parte, la cultura sensu lato, con virtudes y defectos, iniciaba su peregrinar. En todo ese tiempo, el hombre no recibió el mínimo reproche de su acción explotadora y sobreexplotadora.

Las cosas tornáronse diferentes. Pasaron varias generaciones para que el reproche llegara: ahora se reconoce la existencia de una problemática ambiental 
y se reconoce como tal porque afecta a la sociedad, a cada uno de sus miembros, en mayor o menor magnitud. Antes, cuando la sociedad afectaba sin ser afectada, "no había problema".

Los intentos de comprensión y explicación de los problemas ambientales son diversos. Hay quienes argumentan que tienen su origen en el inusitado crecimiento de la población en los últimos tiempos, ${ }^{1}$ lo mismo que en los modos de producción vigentes, que encuentran a través del capitalismo su máxima expresión. ${ }^{2}$ La migración del campo a la ciudad (uno de los factores cruciales en la hiper-concentración de la gente en las ciudades), también se contempló como una causal en el subsecuente decremento de la calidad de vida en las áreas urbanas.

La complejidad de la cuestión ambiental y la dificultad de discernir factores causales, obliga a admitir que las anteriores opiniones adolecen de un nivel explicativo insuficiente. En cierta medida, sirve decir que en la actualidad, con el avance del conocimiento científico y tecnológico, parece que algunos sectores de la humanidad ${ }^{3}$ no tienen límite a su presencia y dominio en el planeta. Pero existe también el supuesto que la tendencia a degradar los sistemas naturales -y sobreexplotarlos hasta su extinción-, se da desde el momento mismo en que los seres humanos ocupan un cierto lugar; ${ }^{4}$ esto ha sido argumentado en diversos trabajos, en donde se asevera que el hombre exhibe conductas agresivas hacia el ambiente; es decir, formas de comportamiento compatibles con una degradación constante del entorno, no necesariamente mediatizadas por la sociedad. Si esto es así, las formas (modos, estilos) del desarrollo humano no deben catalogarse como agentes causal es, sino coadyuvan-

1 Tal es el caso de The population Bomb, de Ehrlich, P.R. (N. York, Ballantine Books, 1968).

2 Así, para el caso latinoamericano, Luis Vitale comenta que el proceso de industrialización de las décadas de 1930 y 1940 en América Latina, fue uno de los principales desencadenantes de la crisis ecológica que vive actualmente el continente. (Luis Vitale, Hacia una historia del ambiente en América Latina. De las culturas aborígenes a la crisis ecológica actual, 1983). Text of Footnote

3 Es inútil hablar de la humanidad como un todo homogéneo. La ciencia y tecnología de vanguardia, y con ello el poder económico, están en manos de una pequeña parte de la población mundial.

4 Trátase de una tendencia a degradar y sobreexplotar la naturaleza, no a "contaminarla", como alegan algunos, en referencia a una actitud de indiferencia, desprecio, hacia el entorno y con efectos en el corto plazo. ...Seguramente sería más enriquecedor reflexionar sobre el cambio en esa racionalidad: en sus inicios, esta tendencia se daba bajo una racionalidad de supervivencia. 
tes, catalizadores, de la crisis ambiental: el modo de producción capitalista, que surge en la Inglaterra de mediados del siglo XVII y se expande rápidamente en el mundo occidentalizado, en efecto, aceleró el ritmo de degradación ambiental y explotación de los recursos, pero la "tendencia deteriorante" es inherente a la esencia humana y se hace presente en todo momento y lugar. Esta aserción, dramática per se, se ve matizada según los diferentes momentos históricos y espacios geográficos en donde se asientan y socializan ${ }^{5}$ los hombres.

La degradación de la naturaleza se ha dado de manera muy heterogénea en la dimensión espaciotemporal y -continuando en la hipótesis conductualen respuesta a conductas que a lo largo del tiempo derivaron en formas de ser; es decir, en patrones cultura- les. En esa lógica, el acto de valorizar (como diferente a valorar) a la naturaleza- es un asunto histórico, que modificó rápidamente el pensamiento de diversas sociedades en las últimas generaciones hacia una ideología de progreso, cristalizando en una cultura sustentada en estrategias de consumo y su extremo, el consumismo. ${ }^{6}$ En tal circunstancia, una propuesta de preservación y conservación de lo natural, y su aprovechamiento equilibrado y estable, hoy inmersa en el neologismo del "desarrollo sustentable", no ha tenido cabida.

Las aproximaciones teóricas al problema del ambiente y su deterioro, así como la búsqueda de alternativas de solución, son relativamente recientes. Tal vez por eso, en la mayoría de ellas se aprecia el aparentemente ineludible "sesgo disciplinario", que lleva a los intelectuales hacia terrenos estrechos para el entendimiento de la cuestión ambiental. De ahí que las explicaciones y eventuales propuestas quedan en niveles intermedios y (esto es lo más grave) raramente viables.

La necesidad de observar marcos analíticos más amplios y de erigir alternativas metodológicas susceptibles de concretarse para el estudio de la cuestión ambiental, lleva implícita la dificultad extrema de reconciliar las aproximaciones unidisciplinarias. La idea del trabajo en equipos integrados por especialistas de diversas disciplinas, en donde todos alimenten y se re-

5 La socialización en sí es un proceso (Zastrow, C., Social Problems. Issues and Solutions, Pág. 29), por lo que lleva implícito el cambio permanente, que modifica en mayor o menor grado la relación sociedad-naturaleza.

6 Enrique Leff comenta sobre la dificultad de incorporar al paradigma económico de la producción los procesos naturales que fundan la producción de los ecosistemas. Es decir, los fenómenos naturales inscritos en la productividad primaria, los cuales carecen de un precio en el mercado (E. Leff, Ambiente y Articulación de Ciencias, pág. 101), Convendría agregar que el hombre, una entidad también natural, se valoriza en el marco del paradigma económico, como un eslabón de los procesos productivos. 
troalimenten con saberes específicos de los demás, deriva en la propuesta de la interdisciplinariedad.

Pero aun el trabajo interdisciplinario no parece ser la alternativa al deterioro del ambiente, al menos como se ha llevado a cabo hasta ahora. Esto no es un asunto insalvable, por utilizarse una aproximación inapropiada; más bien, es evidencia que la metodología de la investigación interdisciplinaria está en proceso de construcción, por lo que, ciertamente, hay algunos obstáculos que no han sido superados. Uno de ellos, tal vez el más difícil de allanar, es el rechazo natural de los especialistas al trabajo pluridisciplinario. ${ }^{7}$

$\mathrm{El}$ asunto ambiental es complejo, transdisciplinario, ${ }^{8}$ por lo que en las condiciones de los paradigmas científicos tradicionales, requiere del enfoque interdisciplinario. Requiere también: a) reconocer que la aproximación al entendimiento de la problemática ambiental debe darse bajo marcos metodológicos y epistemológicos diferentes a los del trabajo disciplinario tradicional; b) que la participación de diferentes disciplinas en un problema complejo ocurra a través de un proceso de articulación de conocimientos específicos sobre un asunto -problema- igualmente específico, a la vez que único. Y es precisamente esto (especificidad y unicidad del problema) lo que dará la pauta para entender la peculiaridad de la articulación de los diversos saberes; c) del concurso de una gama de disciplinas amplia. Es decir, campos de conocimiento tales como economía, biología, sociología, química, ingeniería, política, agronomía, entre otras están ahí, yeso está muy bien; sin embargo, otras disciplinas deben asimismo intervenir y no lo hacen o -lo que es peor-su contribución no es tomada en cuenta.

Reflexionar sobre estos aspectos coadyuvará en la reconstrucción de un marco teórico y metodológico ad hoc para el análisis del asunto ambiental.

En cuanto a la elucidación de conceptos y el surgimiento de alguna metodología aceptable en la cuestión ambiental, poco se ha avanzado. Esto se

7 Ello se puede notar en los foros multidisciplinarios, donde el intercambio de saberes causa cierta angustia en el especialista, puesto que ahí se da cuenta que sobre un problema tan complejo como el ambiental, pocos comprenden y comparten su opinión, y por otro lado, ique él lo entiende menos de lo que creía!

8 Vicente Sánchez, Aparición y evolución de los problemas del medio ambiente, pág. 20. Sobre el particular, Leff define la transdisciplinariedad como "un proceso de intercambios entre diversos campos y ramas del conocimiento científico, en los que unos transfieren métodos, conceptos, términos e incluso cuerpos teóricos enteros hacia otros, mismos que son incorporados y asimilados por la disciplina importadora, induciendo un proceso contradictorio de avance/retroceso del conocimiento que es característico del desarrollo de los conocimientos científicos" (E. Leff, Ambiente y Articulación..., pág. 97). 
toma sumamente riesgoso para la construcción de corpus de conocimiento consolidados. Un argumento irrefutable es que los problemas ambientales han hecho crisis en la sociedad y que como contraparte, el quehacer intelectual tradicional va quedando a la zaga de esa problemática. Así, la crítica que surge desde la academia hacia los "medios" (prensa, radio, televisión), lo mismo que a los tomadores de decisiones, por el escaso o nulo conocimiento del "bagaje eco lógico" que utilizan ambos en sus discursos o en lo erróneo y superficial de las políticas y acciones implementadas por los últimos, encuentra su justificación en la incapacidad misma de los intelectuales de llegar a consensos terminológicos y conceptuales y a propuestas realizables, comunicables al lego, ${ }^{9}$ en contextos socioculturales determinados.

Conviene recordar que el problema ambiental entró en escena, y se reconoció como tal, cuando en el seno mismo de los países industrializados se generó un grave deterioro de los recursos naturales y de la calidad de vida. ${ }^{10}$ Diversos organismos y personalidades de esos países -básicamente de los niveles gubernamentales- han convocado a reuniones desde hace varias décadas. El objetivo (declarado) es encontrar alternativas de solución a las crisis (ecológica, social, del desarrollo) que afectan a toda la humanidad.

$\mathrm{Si}$ bien esos encuentros sirven para generar conclusiones gruesas sobre el estado del ambiente mundial físico y social, ${ }^{11}$ que derivan en consensos (sobre lo que está mal, sobre qué o quién tiene la culpa, sobre lo que debería hacerse y el cómo, y que en los hechos producen algunas acciones aisladas), en el fondo obedecen a fines específicos de las potencias, ${ }^{12}$ quienes discuten más que nada, sobre el estado de la dualidad sociedad-naturaleza, y en cómo ese estado de cosas afecta sus intereses, sus fuentes de recursos. En última ins-

9 “[Preguntando un lego a un consultor sobre un problema técnico]... Usualmente, la falta no radica en quien pregunta, sino en aquellos de las comunidades técnica y científica quienes pueden tener aversión o incapacidad de asumir el problema y expresar la respuesta en términos que el lego pueda entender..." (Ott, W.R., Environmental indices. Theory and Practice; 1978:2) 10 Insertándonos en la óptica del "modelo dependiente", es fácil advertir la gravedad del problema en los países periféricos.

11 Entiendo al ambiente como una construcción social, donde lo físico y lo social se funden en un todo articulado. Hago referencia aquí a dos grandes componentes porque en el entendimiento común sólo se considera a lo físico (no humano) como "el ambiente".

12 Un caso ilustrativo, de actualidad, es el Acuerdo de Cooperación sobre Medio Ambiente, paralelo al Tratado Trilateral de Libre Comercio de Norteamérica, el cual conlleva la imposición -no declarada, por supuesto- de opciones científicas y técnicas (o intelectuales y materiales), y normatividades, compatibles con un modelo económico transnacional, al cual debe someterse todo país que desee incorporarse. 
tancia, tales reuniones sólo han logrado oscurecer el panorama, pues parece ser que el mensaje es que todos tenemos el mismo grado de culpa de lo que ahora pasa en el ambiente, debido a lo incorrecto que actuamos con él. ${ }^{13}$ En ese sentido, nuestras acciones individuales y colectivas han conducido al planeta al estado de deterioro ambiental en que hoy se encuentra.

La evidencia empírica es que los síntomas de ese deterioro ambiental se magnifican en aquellas áreas sometidas a una fuerte presión demográfica y socioeconómica; concretamente, en la instancia espacial de mayor artificialidad lograda por el hombre: la ciudad. Por ello, es una opinión compartida que la crisis ambiental se genera fundamentalmente en las zonas urbanas, ${ }^{14} \mathrm{si}$ bien por situaciones estructurales, irradia efectos en su "hinterland". La vida urbana es, por lo tanto, motivo de gran preocupación en el quehacer ambiental de nuestro tiempo.

Para el estudio de un problema ambiental particular, considero útil un acercamiento bajo un enfoque teórico "no unidisciplinario"; esto es, una estrategia teórica y metodológica multi e interdisciplinaria. En esencia, propondría:

1. Determinar un contexto más comprehensivo, a la vez que concreto, de los agentes que definen la problemática. El análisis sistémico parece ser el más adecuado.

2. Si se ha de buscar causas, entonces deberá atenderse al papel de la conducta como posible causa última.

3. Exponer la necesidad de replantear los paradigmas tradicionales -que encuentran en la especialización la vía de acceso al progreso y desarrollo humano-, a la luz de la crisis ambiental de nuestro tiempo.

4. Considerar las ventajas y los riesgos de la unidisciplinariedad en el trabajo ambiental, justipreciándola como una forma de trabajo necesaria, pero complementaria.

13 La culpa es compartida es cuanto a cosas negativas. Ahí no hay distinciones. Guerras, contaminación, pobreza, delincuencia y muchos problemas más ocurren en todas partes, y esto es por que, se dice, los hombres no han reparado en lo que hacen; las conclusiones a que se ha llegado en muchas reuniones internacionales se dan en tal sentido.

14 Se han propuesto varios criterios para definir lo urbano, y con ello diferenciarlo de lo rural; 1) el número mágico de los 2,500 habitantes o más; 2) la densidad y la mayor concentración en oferta de servicios y bienes; 3 ) la especialización en los sectores secundario y terciario. Lo cierto es que, en comparación al área rural, en la urbana el ambiente social está más alterado, pues sus habitantes, en general, "tienen altos niveles de ingreso y educación, mayor movilidad social, familias más pequeñas, mayor diversidad, matrimonios menos estables, y reporte de más altas tasas de alcoholismo, drogadicción, suicidio y enfermedades mentales" (Zastrow, C. Social Problems..., pág. 539). La proyección de estas condiciones al ambiente físico son cada día más evidentes. 
Se debería partir del supuesto general de considerar al deterioro ambiental como un proceso de degradación de la calidad del ambiente (natural y social), cuya dinámica está íntimamente vinculada a los elementos que lo componen, que son causa a la vez que efecto. Por lo tanto, no existiría una definición única para el deterioro del ambiente, mas que aquella que se da dentro de la propia especificidad del problema que se confronta, en cierta dimensión espaciotemporal. En este tenor, los paradigmas científicos tradicionales, que nacen y se conforman por la fragmentación del conocimiento (y con ésta, de la percepción de la realidad), se toman inviables como apoyos "acabados" para llegar a reconocer, describir, interpretar y explicar la complejidad de un asunto ambiental.

El quehacer unidisciplinario no es algo innecesario, todo lo contrario, pero sí insuficiente. Ello implica que los especialistas (unidisciplinarios) son piezas clave en la actividad interdisciplinaria. En lo que sigue, discutiré algunos fundamentos teóricos y metodológicos para el análisis de la problemática ambiental.

\section{EL CONTEXTO DE LA PROBLEMATICA AMBIENTAL.}

En literatura especializada sobre diversas temáticas, se contempla una preocupación por el estado actual de los recursos naturales y por sus perspectivas de pervivencia en el futuro. Agua, aire, suelo, flora y fauna, así como los fenómenos de contaminación y el deterioro de los recursos resultan ser temas cotidianos. Pareciera que una sincera preocupación por la naturaleza invadiera el espíritu humano en todo el orbe. Inclusive, la cuestión social también se incorpora como parte de la dimensión ambiental. ${ }^{15}$

Pero las opiniones que surgen desde diferentes foros ${ }^{16}$ son poco alentadoras. El informe de la Comisión Mundial sobre Ambiente y Desarrollo -sólo para comentar uno de los más recientes, que ha marcado pautas a seguir en

15 O viceversa, la cuestión ambiental se incorpora como parte de la dimensión social. Lo que no se discute es que lo social es toral en los problemas ambientales de nuestro tiempo, aun cuando no sea contemplado así ampliamente.

16 Baste mencionar algunas reuniones internacionales en donde el asunto ambiental ha sido puesto en la mesa: 1) Congreso Constitutivo de la Unión Internacional para la Conservación de la Naturaleza (Fontainebleau, Francia, 1948); 2) Reunión de Founex (Founex, Suiza, 1971); 3) Conferencias Regionales de las Naciones Unidas sobre Medio Humano (México y Praga, entre otras, 1971); 4) Conferencia de la ONU sobre el Medio Humano (Estocolmo, 1972); 5) Seminario de Cocoyoc (Cocoyoc, México, 1974); 6) Reunión Mundial del Programa de las Naciones Unidas para el Medio Ambiente (Nairobi, 1982); 7) Conferencia de la ONU sobre el Medio Ambiente y el Desarrollo, o Cumbre de la Tierra (Río de Janeiro, 1992); 8) Conferencia Regional de la ONU sobre Población y Desarrollo (México, 1993); 9) Conferencia de la 
todo el mundo-, también conocido como Informe Brundtland, ${ }^{17}$ nos devela la cruda realidad: la naturaleza y sus recursos deben preservarse y conservarse para asegurar su aprovechamiento por parte de las generaciones futuras. En efecto, no hay razón para pensar en una "ética del ambiente" que emane de las propuestas sobre la sustentabilidad del desarrollo que nos ofrece G.H. Bruntland y sus colaboradores. La sugerencia va dirigida en todo caso, a implementar una mejor racionalidad de utilización para garantizar que las generaciones venideras disfruten lo que hoy está dado.

También esa propuesta del desarrollo sustentable aclara que no hay crisis separadas, que la crisis ambiental es una sola. La falsedad de la postura estriba en que busca el adoctrinamiento, rematando que en la crisis ambiental todos somos culpables por igual, los del norte y del sur, industrializados y no industrializa- dos, desarrollados y no desarrollados, ricos y pobres; todos compartimos la misma culpa. Asimismo, el Informe declara que la pobreza contamina -idea que se esbozó también en la reunión de Estocolmo (1972)- y que junto con el crecimiento económico, se convierten en los principales agentes causales de la crisis ambiental. Al margen de una clara direccionalidad ideológica en el discurso, es manifiesta su limitada visión sobre la cuestión ambiental, puesto que en ella el hombre sigue siendo dominante y ajeno al ambiente.

\section{EL SUPUESTO PAPEL DE LA CONDUCTA}

Autores menos comprometidos, dan pistas más aceptables: hay quienes aseveran que la tarea cotidiana del hombre, desde sus inicios, ha sido la de sobreexplotar la naturaleza para su máximo beneficio. ${ }^{18}$ Si esto es así, entonces, la subsecuente degradación de los sistemas naturales y sus recursos, que indudable- mente ha tenido un factor detonante en la racionalidad económica moderna, llámese capitalista o cualquier otra, ${ }^{19}$ tendría una causal más profunda, que

ONU sobre Población y Desarrollo (El Cairo, 1994); 10) Conferencia Mundial sobre Desarrollo Social (Copenhague, marzo de 1995).

17 The World Commission on the Environment and Development, Our Common future, 1987.

18 Por ejemplo, en su trabajo de 1993, Ludwig, Hilborn y Waters parten de la premisa que, a lo largo de la historia, los recursos han sido sobre explotados hasta el punto de la extinción. Esta es una aseveración que en esencia, modifica la tradicional concepción de que el agotamiento de los recursos se produjo en las últimas décadas del presente siglo, como resultado del modelo económico vigente y su racionalidad productiva.

19 Montes y Leff anotan que las catástrofes ecológicas se han dado desde la formación misma de la tierra, no como hechos propios de la civilización contemporánea; aunque ésta, 
es la tendencia natural del ser humano a sobreexplotar, a veces con efectos irreversibles, todo aquello que en su momento denomina "recurso" y junto con él, a causar daños paralelos al ecosistema en donde se encuentra el bien en cuestión. Ello indica que debe ponerse atención a la zona de umbral que la psicología y la sociología no han enfrentado: la exteriorización de las conductas individuales en el ambiente social y su efecto en el sustrato físico ${ }^{20}$.

Las conductas exhibidas por los miembros de una sociedad en su cotidiana interacción con el entorno, devienen en dos niveles de análisis: el individual y el colectivo. El primero cuestiona la manera en que el individuo manifiesta una proclividad a desdeñar "lo ajeno" y por ende, lo daños que ocasione a su alrededor; el segundo, se refiere al accionar de la sociedad en su conjunto como motor de cambios, irresponsable de consecuencias ambientales, las más de las veces funestas. En esos niveles, los estudios antropológicos, psicológicos y sociológicos brindan el marco de análisis fundamental. ${ }^{21}$

En años recientes, algunos autores han dado un brusco cambio en las aproximaciones de lo social a la cuestión ambiental. ${ }^{22}$ La sugerencia es buscar las causas de fondo al interior de las sociedades, ya no basarse tanto en su expresión externa, en lo que hacen al ambiente. En otras palabras, las interrelaciones de los individuos en una sociedad nos dirán mucho más sobre las causas de los problemas ambientales, que el cómo se interrelacione el individuo o la colectividad, con el ambiente físico.

Esta idea, que podría denominarse de "mirar hacia adentro", nos lleva a una interrogante: ¿qué tan adentro? O sea, si bastará con analizar los vínculos interindividuales, como dadores de la respuesta mejor, o si sería conveniente ir más

a lo largo de su historia, ha transformado la naturaleza en función de los usos sociales y productivos que se han dado a sus recursos. "Las crisis ecológicas, sin embargo, ocurren a partir de los efectos de la mundialización de un proceso de crecimiento fundado en la acumulación de capital, en los procesos tecnológicos y en los modelos de consumo que han sostenido y orientado el desarrollo de las fuerzas sociales de producción sobre la base de una apropiación desigual y destructiva.

20 La aportación de Gamiochipi (Orígenes psicológicos y psicopatológicos del deterioro ambiental, 1982: 44-58) apunta en ese sentido.

21 Sin ser una lista exhaustiva, cabe recordar a Robert Ardrey, Emile Durkheim, Edward, T. Hall, George Homans, Konrad Lorenz, Karl Marx, Georg Simmel, S.L. Washburn y Louis Wirth, cuyas contribuciones de alguna manera dejan entrever el accionar, individual y colectivo, del hombre en su entorno.

22 Bookchin, por ejemplo, reconoce que los problemas ecológicos tienen una causal última de tipo social. En este sentido invita a cavilar sobre lo inapropiado de buscar en la relación naturaleza-sociedad las causas de los problemas ecológicos y no al interior de la sociedad misma (Bookchin, R. Remaking Society, 1990). 
hacia adentro, al interior del individuo, como condicionador (y condicionado) de la exteriorización de su conducta y por ello, de su interacción con otros individuos. Sin ánimo de continuar la discusión entre las posiciones individualista y holista para la explicación de lo social, ${ }^{23}$ debe reflexionarse sobre la luz que estos enfoques teóricos pueden aportar hacia el entendimiento de la cuestión ambiental.

Finalmente, en lo que todos estaríamos de acuerdo es que toda esa dinámica de uso y abuso de lo que está en el entorno y se percibe como "dado", sin reparar en consecuencias indeseables, y con el único fin de maximizar ganancias en tiempos cortos, deviene en "un proceso constante y acelerado (más en algunas regiones que en otras) de degradación de las condiciones físicas y sociales del ambiente: el Deterioro Ambiental. ${ }^{24}$ Las variables espacial y temporal quedan implicadas en el proceso.

\section{LA TAREA DE GENERAR Y ADQUIRIR CONOCIMIENTOS SO- BRE LO AMBIENTAL.}

A raíz de las señales de alarma que surgieron hace más de treinta años, en los países industrializados, en relación con los conflictos ambientales que se gestaban por causa de una actividad humana ${ }^{25}$ incompatible con el equilibrio de la naturaleza, desde diversas disciplinas se ha replanteado la complejidad que significa confrontar un asunto ambiental, y en la incapacidad de que -bajo los paradigmas científicos prevalecientes-, se llegue a obtener una pronta solución.

Tal parece que el ideal del progreso a través de la razón, la ciencia y la tecnología, al final del siglo XX ha quedado desenmascarado en su real imagen: ${ }^{26}$ la polarización del mundo, con su norte rico y el sur pobre, con países "centrales"

23 Tampoco se pretende adoptar la corriente sociobiológica, cuyas virtudes y defectos son, asimismo, fuente de polémica.

24 Santes-Alvarez, R. Deterioro Ambiental en la Región del Rio Blanco, Veracruz, 1993. Esta es una definición muy general; pero esa generalidad resulta del hecho que, como ya se comentó, solamente la especificidad de los agentes causales puede darnos la especificidad de la definición.

25 Económica, fundamentalmente; no obstante que algunos salieran en defensa y descargo de la racionalidad productiva imperante, aduciendo que el crecimiento de la población, sobre todo en los países del "Tercer Mundo" era una de las causas del problema ecológico global. En este sentido, la pobreza se manejó, desde entonces y hasta ahora, como una causa, no como un efecto de la crisis ecológica (cfr. Informe Brundtland, 1987, op. cit.).

26 "El siglo XX comprobó azorado que el sueño del progreso no condujo a la libertad social e individual, sino al control más estricto a través de las ideologías, las burocracias, 
y otros. "periféricos"; unos industrializados y otros no industrializados (o en vias de industrialización). Hoy, los ricos cada vez son menos, pero más ricos; los pobres cada vez más, y más pobres.

En este escenario, los intelectuales se han visto en la necesidad de revisar los paradigmas tradicionales, cuestionarse si la especialización y la subsecuente formación de una gran diversidad de disciplinas sir- viera ahora para presentar alternativas al deterioro del ambiente. ${ }^{27}$ Las conclusiones no son muy halagüeñas. Los especialistas dan solamente soluciones parciales en el mejor de los casos, porque la complejidad de los asuntos ambientales (de los sistemas ambientales) re- basa su campo cognoscitivo. Frecuentemente, la con- junción de varios especialistas en un estudio de caso, deriva en una gama de soluciones, tantas como especialistas participen en la investigación.

El tratar lo ambiental como un sistema complejo ha implicado retomar el pensamiento de Bertalanffy ${ }^{28}$ y otros, iniciadores de la teoría de sistemas. Hoy se ha avanzado mucho trecho, y lo que en un principio fue exclusividad del campo de los "fisicalistas", ahora tiene utilización más extensa. La dialéctica hegeliana y fundamentalmente la corriente del materialismo dialéctico de Marx, han tenido mucho peso en esta aproximación sistémica. Las propuestas de Rolando García conllevan un análisis epistemológico y metodológico de los sistemas complejos sumamente enriquecedor, incorporando presentaciones empíricas muy sugerentes. ${ }^{29}$

Los conceptos y la metodología ambiental, no obstante, están poco elaborados y carecen de una aceptación amplia, de manera que la incapacidad de lograr consensos entre los científicos es todavía uno de los mayores obstáculos para encarar los problemas del deterioro ambiental en su real magnitud. Estos problemas, se insiste, están rebasando la capacidad de res- puesta de los intelectuales, la sociedad y los gobiernos de todo el mundo, por lo que su atención prioritaria es el reto actual.

las instituciones [...]...La teoría de la decadencia como hundimiento, ruina, y degradación de todo lo existente, no es más que el resultado de la teoría del progreso que atrapó a todas las sociedades. La decadencia expresa un rompimiento entre el modelo soñado y la realidad concreta." (Gabriel Careaga El Siglo Desgarrado. Crisis de la Razón y la Modernidad, pp. 140 y 166). 27 Enrique Leff, Ambiente y Articulación..., pág. 78).

28 Bertalanffy, L., Teoria General de Sistemas, F.C.E., México, Madrid, B. Aires., 1976.

29 Conceptos básicos para el estudio de sistemas complejos, 1986, pp. 45-71; Modernización en el agro: ¿Ventajas comparativas, para quién?, 1988; Deterioro ambiental y pobreza en la abundancia productiva (el caso de la comarca lagunera), 1988. 


\section{EL TRABAJO AMBIENTAL, ¿UNIDISCIPLINA VS. INTERDISCI- PLINA?}

Se ha comentado que un problema ambiental, que se da dentro de un sistema ambiental, posee tal nivel de complejidad que no resulta una tarea sencilla siquiera reconocerlo y delimitarlo de inmediato.

Pongamos por ejemplo, la contaminación de un río por ciertas sustancias químicas provenientes de una zona industrial. En un intento de investigación integral, un estudioso del ambiente se encontraría con varios retos, entre otros, los siguientes: 1) determinar el tipo y concentración del contaminante; 2) señalar posibles fuentes emisoras; 3 ) definir la dirección y la velocidad de desplazamiento del material químico y su tiempo de residencia en la columna, así como su relación con el sedimento; 4) tipificar el suelo y reparar en la posibilidad de infiltración del químico hacia el manto freático; 5) alertar sobre el grado de riesgo en el uso del agua para fines domésticos, e indagar sobre las afectaciones actuales; 6) determinar la factibilidad de uso de sistemas tecnológicos de tratamiento de los efluentes o en su defecto, sobre el uso de cauces alternativos; 7) en caso de vecindad con un sistema agroproductivo, encontrar afectaciones actuales o potenciales; 8) sugerir la aplicación de la normatividad que el caso demande; 9) proponer los mecanismos de gestión ante las empresas (u otras agrupaciones) con argumentos suficientes, acerca del daño que se ocasiona y la obligación de resarcirlos; 10) plantear alternativas económicas "satisfactorias" a la de máximos beneficios y mínimos costos; 11) definir los mecanismos de satisfacción de eventuales demandas sociales emanadas del problema que se confronta; 12) en base al resultado, proponer la actualización de las políticas y normatividades.

Para cubrir estos retos, el estudioso del ambiente debiera optar por integrar un equipo de trabajo, en donde se encontraran químicos, ingenieros hidráulicos, agrónomos, geólogos, hidrólogos, licenciados en derecho, economistas.

En realidad, si se diera una propuesta de resolución viable al problema ejemplificado, ésta la daría un administrador ambiental; ${ }^{30}$ pero no porque él por sí solo, la hubiese formulado: esta respuesta surgiría en el marco de un

30 Un funcionario público vinculado a asuntos sobre ecología, desarrollo urbano, población, contaminación, agricultura, salud, entre otras responsabilidades, sería un administrador del ambiente. Aunque él no lo sepa, o no lo entienda así, su función es vigilar por el devenir de un ambiente -entendido como construcción socia/- apropiado. Los organismos privados o no gubernamentales pueden contar con personas de amplios conocimientos sobre cuestiones ambientales; pero en la medida que no posean capacidad para tomar decisiones e implementar políticas de gestión ambiental, no tendrán las perspectivas del administrador (funcionario) público. 
exitoso trabajo de equipo. Como se adivina, ante un problema aparentemente tan acotado (la contaminación de un río), ${ }^{31}$ la propuesta de solución que ofrezca un especialista podría ser buena, pero no la mejor ni con mucho la más completa. Veamos por qué:

Los profesionistas actuales, formados en campos disciplinarios específicos, tal vez con justificada razón tratan de encontrar respuestas a los problemas plantea- dos en un sistema ambiental complejo, al interior de su disciplina. Desafortunadamente, en la mayoría de los casos, los resultados han sido respuestas parciales a problemas complejos, que por causa de un ineludible sesgo disciplinario, han traído como consecuencia un desprendimiento absoluto del problema básico, pues éste no fue definido y aprehendido correctamente desde el inicio de "la investigación". No obstante, es usual que en una investigación el problema complejo se fraccione en problemas aislados, donde el profesionista pueda dar la mejor respuesta y propuesta de solución (...desde su perspectiva, claro está), dejando fuera elementos de análisis más importantes (¡en don- de podrían estar los agentes causales, inclusive!). De ahí que la presencia de un personaje con visión "menos especializada", que coordine el trabajo, es una necesidad básica, si bien "rara" de satisfacer. ${ }^{32}$

A pesar de todo, la labor especializada es funda- mental, pues en la cuestión ambiental ocurren interrogantes muy específicas, a las cuales solamente una disciplina en particular puede dar respuesta. Posterior- mente, esta respuesta se incorporará en una más completa, al problema ambiental tratado.

La integración de equipos multidisciplinarios con aspiraciones al trabajo sustentado en la interdisciplinariedad, se presenta ahora como la alternativa. El surgimiento de programas e inclusive centros de investigación en di-

31 En efecto, para Rolando García (1994:85) este sería un problema "local y circunscrito" que -desde su perspectiva- no adquiere el carácter de interdisciplinario. Sin embargo, al revisar los doce retos a que alguien interesado en este problema ambiental se enfrentaría en la situación descrita, nadie dudaría de que se encontrara con problemáticas inherentes al "medio físico-biológico, la producción, la tecnología, la organización social, la economía" en confluencia, características éstas que, según ese autor, definen un sistema complejo, en donde sí se da la interdisciplinariedad (cfr. R. García, Interdisciplinariedad y sistemas complejos. En: Leff, E., Ciencias Sociales y Formación Ambiental).

32 "[El planificador ideal] sería alguien con un entrenamiento científico básico, que poseyera experiencia en trabajos de protección ambiental a través de varios campos (es decir, una persona con la inteligencia necesaria en todos los aspectos ambientales relevantes). Sin embargo, tales individuos son raros..." (Sven-Olof Ryding, Environmental Management Handbook, 1994: 639). 
ferentes países que se adjudican el carácter de multidisciplinarios, ${ }^{33}$ parece ser un reconocimiento tácito de las deficiencias mostradas por las disciplinas tradicionales, producto del paradigma Newtoniano-Cartesiano ${ }^{34}$ en la explicación de problemas en sistemas complejos. Sin embargo, es necesario decir algo sobre el asunto.

El hecho de que un problema complejo sea confrontado por un grupo de profesionistas de diferentes disciplinas que se encargan de partes distintas del problema y luego dan "respuesta" a la parte que les correspondió no es una solución feliz, ni mucho menos es el significado de la interdisciplinariedad. También, el que un problema acotado, muy específico, sobre una cuestión ambiental, sea analizado por un equipo pluridisciplinario (multidisciplinario) en donde cada quien dé "su respuesta" al todo, no significa trabajar interdisciplinariamente.

Desafortunadamente, esas han sido las formas de "solucionar" problemas ambientales en la mayoría de las veces "bajo una óptica interdisciplinaria”.

El quehacer interdisciplinario es algo más elaborado. Frecuentemente, los acercamiento $s$ en este sentido quedan en "buenas intenciones" porque implican: a) cuestionar paradigmas tradicionales; $b$ ) trabajar a "mente abierta” sin menoscabo de reconsiderar posturas teóricas o metodológicas preformadas; $c$ ) actuar cooperativamente, intercambiando información y conocimientos; $d$ ) interactuar con colegas de diversas formaciones disciplinarias; y e) arriesgarse a sufrir la crítica y hasta la exclusión de círculos disciplinarios "de élite".

En la situación descrita, son pocos los que aceptan el reto. Pero si el asunto es satisfactoriamente salvado, se habrá avanzado mucho camino. ...Falta más.

Al reunirse el grupo de trabajo, éste tiene el status de pluri o multidisciplinario. El carácter de interdisciplinario se adquiere durante el proceso de la investigación. Esto es así y no de otra manera, porque la interdisciplinariedad es un proceso dialéctico, de constante comunicación, trabajo grupal, intercambio de opiniones, toma de posición, reflexión y reconsideración del trabajo y resultados acumulados.

Lo anterior implica ciertas condiciones y varios supuestos. En primer lugar (y esto no es una obvie- dad), la existencia de un problema en un siste-

33 Insto de Investigación de las Naciones Unidas para el Desarrollo Social; Programa de Análisis de Cambios en la Biosfera, de la Federación Internacional de Institutos de Estudios Avanzados; Programa LEAD de Desarrollo Sustentable, de El Colegio de México; Institute for Environmental Studies, de la University of Toronto; Instituto de Ciencias del Hombre (Madrid); varios centros de investigación multidisciplinaria, de la UNAM, entre otros.

34 Miguel Martínez Miguelez, El Paradigma Emergente, Gedisa, 1993. 
ma ambiental (complejo). Aceptar que el problema existe implica buscar su identificación. En otras palabras, emitir una pregunta conductora: ¿cuál es el problema? En cuanto el grupo de trabajo reconozca las fronteras, los límites, del problema, se habrán avanzado otro trecho. ${ }^{35}$

La concepción del problema implica una construcción del objeto de estudio $^{36}$ y conlleva la determinación de prioridades, en aras de su resolución. Idealmente, el nivel de prioridades debe estar en función de la investigación y no de causas ajenas. ${ }^{37}$ Esta situación raramente se cumple, pero es conveniente tenerla presente. Por otra parte, las prioridades que defina el grupo interdisciplinario conducen a la delimitación del problema en términos conceptuales, pero también espaciales y temporales. La tarea de alimentación y retroalimentación de conocimientos a través del ejercicio interdisciplinario adquiere una dinámica propia.

Lo hasta aquí comentado refleja únicamente las etapas iniciales de una investigación que asume el reto de convertirse en interdisciplinaria. Efectivamente; la intención de estas líneas ha sido mostrar que la empresa se avizora compleja desde un principio. Pero el autor no percibe manera diferente de confrontar un problema ambiental. Si esta vía es la mejor, con los bemoles que implique habrá que recorrerla.

35 Rolando García hace referencia a las dificultades para llegar a delimitar un problema ambiental (García, R., op. cit.); en el proceso está implícita la responsabilidad de determinar qué es lo que entra y qué no, en la investigación.

36 Bourdieu et. al., El Oficio del Sociólogo, 1994:54. (37)

37 Desafortunadamente, las prioridades de una investigación las define el científico y, toda vez que se trata de alguien formado bajo ciertos esquemas cognoscitivos, éstas obedecen a tales esquemas. Esta es una observación importante, pues se corre el riesgo de que la investigación se encasille en un campo académico particular, situación que para un asunto ambiental ¡es la negación de su comprensión!. Con ello se determinan "prioridades de la investigación" ajenas al problema mismo. Un breve pasaje del diálogo entre "A" y "B" en una obra de Feyerabend, sustenta esta mención: "B. [...] Piensa en los científicos que trabajan en un cierto campo de investigación. Parten de supuestos básicos que casi nunca ponen en duda, consideran sus métodos experimentales como si fuesen los únicos procedimientos lógicos; y la investigación consiste en utilizar métodos y supuestos básicos, no en analizarlos [...] Hoy [...] las investigaciones se definen según unos supuestos de los que ya no se es consciente..." (Paul Feyerabend, Diálogo sobre el Método, 1990:40-41). 


\section{EL TRABAJO AMBIENTAL, ¿A LA BUSQUEDA DE UNA NUEVA UTOPIA?}

Los tiempos actuales nos muestran las consecuencias de un anterior período de indiferencia e ignorancia acerca de la relación entre una sociedad occidentali$z a d a$ y la naturaleza. La crisis que ahora nos aqueja se fue gestando durante los últimos siglos de existencia humana como resultado de una racionalidad de uso y abuso de lo que el sistema natural nos brindaba. ${ }^{38}$

Lo que en sociedades anteriores era claridad, cooperación y cuidado, en las actuales se tornó en ambigüedad, competencia e inconsciencia. ${ }^{39} \mathrm{El} \mathrm{hom-}$ bre de nuestro tiempo confronta grandes indefiniciones, pues los valores, las normas, la magia con la que creció, la ideología del progreso, sus expectativas; sin poder explicárselo se han convertido en simples utopías.

En el afán de hacer a la naturaleza objeto de sus intereses, el hombre se ha olvidado de que él también forma parte de ella, y que con esa desafortunada tendencia a "cosificar" al mundo se cosificaba él también.

El hombre- $\operatorname{cosa}^{40}$ marca el inicio de su carrera en el Renacimiento y parece que al final del siglo XX llega a una meta no prevista, plagada de incertidumbre y desasosiego. Aquella de la igualdad, el bienestar y la felicidad a través de la razón quedó en otra parte, en el mar de las utopías.

Pero alejémonos un poco de esa visión tan pesimista del mundo. Determinemos qué tan catastrófica es la situación, definamos su magnitud y sus alcances, pensemos en algunas alternativas a todo lo que hemos heredado, lo que hemos cambiado y lo que estamos heredando a nuestros descendientes. ${ }^{41}$ Hay mucho por hacer.

El ejercicio intelectual requiere de soportes empíricos que lo retroalimenten y redireccionen. En este sentido, con la convicción de coadyuvar a encontrar los caminos para llegar a un futuro mejor, y desarrollar una metodología

38 El pensamiento de gente como Locke, Newton, Descartes, entre otros, influyó en la visión antropocentrista del mundo en la cultura occidental.

39 Murray Bookchin, Remaking Society.

40 Ernesto Sábato, Hombres y engranajes, 1973.

41 La proclama de que este mundo "no lo heredamos de nuestro padres sino que nos fue prestado por nuestros hijos”, tan corrompida por muchos, podríamos visualizarla desde otra ventana, con serios cuestionamientos: ¿es el mundo de hoy -tal como está- el que prestamos a nuestros padres y abuelos, cuando veíamos las primeras luces?; o ¡es el mundo de hoy -tal como está- el que nos han prestado nuestros hijos que apenas nacen o nuestros nietos que pronto nacerán? 
acorde a la circunstancia ambiental de nuestro tiempo, es necesario hacerse a la búsqueda de problematizaciones particulares, ilustrativas del estado de crisis de la dualidad hombre (sociedad)-naturaleza.

El trabajo puede desarrollarse en áreas urbanas o rurales, municipalidades, estados o regiones. La estrategia y temporalidad de las investigaciones deberá enmarcarse en el contexto mismo de la problemática teórica planteada. De inicio se vislumbra que la problemática ambiental que se considere, compleja en esencia como aquí se ha visto, se complicará aún más al incorporar, necesariamente, relaciones intersistémicas entre variables. Pero esto es motivo de una subsecuente reflexión.

\section{BIBLIOGRAFIA.}

Ardrey, R., La evolución del hombre: la hipótesis del cazador, Alianza Editorial, Madrid, 1978,254pp.

Bertalanffy, L., Teoria General de Sistemas, F.C.E., México, Madrid, B. Aires., 1976.

Bookchin, R., Remaking Society, South End Press, Boston, MA., 1990.

Bourdieu, P., Chamboredon, J-P y J-P Passeron, El Oficio del Sociólogo, Siglo XXI, 1994.

Careaga, G., El Siglo Desgarrado. Crisis de la Razón y la Modernidad, Cal y Arena, México, 1988, 175 pp.

Durkheim, E. Las reglas del método sociológico, F.C. E., México, 1986, 205 pp.

Ehrlich, P.R., The population Bomb, Ballantine Books, N. York, 1968.

Feyerabend, Paul, Diálogo sobre el Método, Ed. Cátedra, 1990.

Gamiochipi, L., Orígenes psicológicos y psicopatológicos del deterioro ambiental; en: López Portillo y Ramos, Manuel (comp.) El medio ambiente en México: temas, problemas y alternativas, F.C.E., 1982, pp. 44-58

García, R., Conceptos básicos para el estudio de sistemas complejos, en: E.Leff (coord.) Los problemas del conocimiento y la perspectiva ambiental del desarrollo, Siglo XXI, 1986, pp. 45-71.

Modernización en el agro: ¿Ventajas comparativas, para quién? El caso de los cultivos comerciales en el Bajío, UNRISD/IFIAS/CINVESTAV, México, 1988.

---- ----- Deterioro ambiental y pobreza en la abundancia productiva (el caso de la comarca lagunera), IFIAS/CINVESTAV, México, 1988.

-.-- -.--- Interdisciplinariedad y Sistemas Complejos; en: E. Leff (comp.) Ciencias Sociales y Formación Ambiental, Gedisa, España, 1994: 85124. 
Hall, E. T., La dimensión oculta, Siglo XXI, México, 15a. ed., 1993, 255 pp. Homans, G., El conductismo y después del conductismo; en: Giddens, A. y Turner, J., La teoría social hoy, Alianza Editorial, COANCULTA, 1990, pp. 81-111

Leff, E., Ambiente y Articulación de Ciencias; en: E. Leff (coord.), 1986, pp. $72-125$.

(coord.), Los problemas del conocimiento y la perspectiva ambiental del desarrollo, Siglo XXI, 1986.

1994.

López Portillo y R., Manuel (comp.) El medio ambiente en México: temas, problemas y alternativas, F.C. E., 1982

López P., M. Y Luis Suárez, Medio ambiente y desarrollo; en: López Portillo y Ramos, Manuel, 1982: 25-43.

Lorenz, K. Evolución y modificación de la conducta, Siglo XXI, México, 12a. ed., 1986, 120 pp.

---- .---- Sobre la agresión: el pretendido mal, Siglo XXI, México, 17a. ed., $1989,342 \mathrm{pp}$.

Ludwig, D, Hilborn, R., and Carl Waters, Uncertainty, Resource Expoitation, and Conservation: Lessons from History, Ecological Applications, 3(4): 547-549, 1993.

Martínez Miguelez, Miguel, El Paradigma Emergente, Gedisa, España, 1993. Montes, J. Ma. y E. Leff, Perspectiva ambiental del desarrollo del conocimiento; en: E. Leff(coord.), 1986, pp. 22-44.

Ott, W.R., Environmental Indices. Theory and Practice. Ann Arbor Science Pub. Inc., Ann Arbor, Mich., 1978.

Ryding, Sven-Olof, Environmental Management Handbook, IOS Press/ LEWIS Pub., Amsterdam/Florida, 1994,777 pp.

Sábato, E., Hombres y engranajes, Alianza Editorial, Madrid, 1973, 200 pp.. Sánchez, V., Aparición y evolución de los problemas del medio ambiente; en: López Portillo y Ramos, Manuel, 1982: 11-23.

Santes-Alvarez, R., Deterioro Ambiental en la Región del Río Blanco, Veracruz, Tesis de Maestría en Estudios Regionales, Instituto de Investigaciones “Dr. José Ma. Luis Mora”, octubre 4 de 1993.

Simmel G., La metrópolis y la vida mental; en: Bassols, M., Donoso, R., Massolo, A. y A. Méndez, Antología de sociologia urbana, UNAM, México, 1988, pp. 47-61.

Vitale, Luis, Hacia una historia del ambiente en América Latina. De las culturas aborígenes a la crisis ecológica actual. Nueva Sociedad, Ed. Nueva Imagen, México, 1983. 
Washbum, S.L. y R. Moore, Del mono al hombre, Alianza Editorial, Madrid, 1986, 233 pp.

Wirth, L., El urbanismo como modo de vida; en: Bassols, M., Donoso, R., Massolo, A. y A. Méndez, Antología de sociología urbana, UNAM, México, 1988, pp. 162-182.

World Commission on the Environment and Development, Our Common future, Oxford Univ. Press, Oxford, 1987.

Zastrow, C. Social Problems. Issues and Solutions, 3thd. ed., Nelson-Hall Publishers/Chicago, 669 pp. 1992. 